\title{
Going for Brokerage: A Task of 'Independent Support' or Social Work?
}

\section{Peter Scourfield}

Peter Scourfield qualified as a social worker in 1984. Having worked in various statutory social work settings, he now works in the Faculty of Health and Social Care at Anglia Ruskin University. His chief teaching and research interests are concerned with the adult social care system and social work with older people.

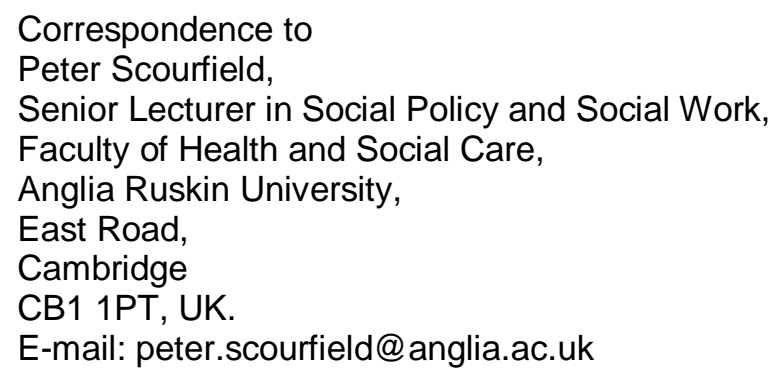

\section{Summary}

It is argued that for the agenda to 'personalize' social care in the UK to be successful, adequate systems of support brokerage need to be in place. Where brokerage is situated organizationally and ideologically is not inconsequential, both in terms of the accountability, profile and quality of the 'brokers' and the extent to which service users can feel properly in control of their own care or support. Many involved in support brokerage argue that independence from statutory bodies is a key principle. However, models of support brokerage have been suggested that propose brokerage as a possible function of the statutory social care sector. The paper traces how and why the 'new' language of brokerage has emerged in official discourses of adult social care. It also discusses the various ideas about what brokerage is and who is supposed to undertake it. It is considered whether support brokerage should be regarded as a form of social work, which is not currently the case. Were independent support brokerage to expand its role in the adult social care system, the question would arise of where that would leave social work with adults. These developments expose conflicts and tensions in New Labour's modernization agenda.

Keywords: Care management, social care, privatization, social support, community care

\section{Introduction}

Embedded in the discourse of personalization in adult social care in the UK are many references to notions of 'support', 'brokerage', 'service brokerage' or 'support brokerage' (there are several variants). Almost all recent reports or commentary on the subject (e.g. Pearson, 2006; Davey et al., 2007a, 2007b; Dowson, 2007; Rabiee et al., 2008), highlight the existence of some form of independent support and/or 'brokerage' as vital for ensuring that individual funding schemes such as Direct Payments (DPs), and their successors, Individual Budgets (IBs), work effectively for those who receive them. ${ }^{1}$

'Brokerage' is now considered a critical element in ensuring the success of the personalization agenda. Therefore, where it is situated organizationally and ideologically is not inconsequential both in terms of the accountability, profile and quality of the 'brokers' and the extent to which service users can feel properly in control of their own care or support. Many involved in support brokerage argue that, to achieve maximum service user control, the broker should be accountable solely to the individual. Consequently, independence from statutory bodies is a key principle. Many are also against professionalizing the service for similar reasons (Reynolds, 2006; Dowson, 2007).

However, historically, there have been instances in which brokerage has been discussed as a function of the statutory social care sector. This was most noticeable when care management was first introduced in the early to mid 1990s (Payne, 1995). After a decade or so of near 
silence on the subject, talk of social care workers taking on some form of broker or navigator role has seen a marked revival in recent years (Commission for Social Care Inspection (CSCl), 2006; Cornes, 2006; Department of Health, 2007, 2008b; Henwood and Walker, 2007).

The initial purpose of this paper is to trace how and why the 'new' language of brokerage has emerged in official discourses of adult social care. In doing so, the paper also discusses the various ideas about what brokerage is and who is supposed to undertake it. Consideration is given to whether support brokerage should be regarded as a form of social work-a situation about which there currently appears to be a considerable degree of confusion.

By not being regarded as social work, brokerage is currently free to regulate itself and to develop its own benchmarks, codes of practice and knowledge base. Care management, on the other hand, because it is identified as 'social care work', is more tightly bound by specific occupational standards, registration and training requirements. It is understandable that independent support organizations want to build and protect their territory. However, at the same time, statutory social care workers want to reinvent their role in ways that make it more interesting and fulfilling. The emergence of a broker role offers potentially exciting possibilities to both sectors. However, it is unlikely that brokerage can belong to both of these arenas at the same time. The current situation is characterized by a lack of clarity about the future direction of this increasingly important role in personalized social care. This is not in the interests of any part of the adult social care system, particularly service users. It means that, amongst other things, critical workforce issues of funding, training, quality, effectiveness and accountability are all far from settled. Were the role of independent support brokerage to expand significantly in the adult social care system, the question would arise of where that would leave social work with adults. These developments expose conflicts and tensions in New Labour's modernization agenda.

\section{Brokerage, personalization, modernization and social work}

The term 'brokerage' has come to prominence in the context of adult social care because of its relevance to the personalization agenda. Although the actual term is never used in Modernising Social Services (Department of Health, 1998), 'personalization' is a clearly traceable development from New Labour's agenda to 'modernize' social services (Leadbetter, 2004; Ferguson, 2007). A decade into modernization, it might reasonably be assumed that the appeal of a term like 'brokerage' is precisely because it speaks of markets, consumerism and entrepreneurship and has no obvious links historically to either social work or the public sector. As Ferguson (2007) has explained, the popularity of the personalization agenda for New Labour is precisely because it is predicated on a marketized and privatized system of social care, and one that involves 'individualization, responsibilization and the transfer of risk from the state to the individual' (Ferguson, 2007, p. 387).

A cynic might argue that the process of shifting risk and responsibility to the individual is timely for the government, because evidence continues to show that in terms of affordable, formal care provision, there is very little out there for anyone to actually 'broker'. It is still the case that the system is propped up by millions of informal carers (Resolution Foundation, 2008). Already, concern has been expressed that personalization could become yet another means of cutting costs (Beresford, 2008).

The emergence of both 'personalization' and its concomitant 'brokerage' further exposes the diverging strands in the modernization agenda. On one hand, modernization is presented as a project of 'professionalization', brought about by the introduction of occupational standards, national minimum standards, the registration of social care workers and enhanced regulation and inspection regimes (Department of Health, 1998; Langan, 2000). However, on the other hand, by its endorsement of independent support and brokerage with their more flexible practices and relaxed standards, New Labour seems to be opening the door to more deprofessionalization. ${ }^{2}$ At the time of writing, there is a sense of two divergent strands unravelling at the same time, with little thought given to how they can be reconciled. 
Therefore, this discussion takes place in a policy context that is clearer on broad aims than on the specific means to achieve those aims. Current official discourse on brokerage is mainly concerned with 'headlines'. Messages from government and elsewhere, about what exactly brokerage is supposed to be and who is going to undertake it are currently ambiguous, uncertain and, at times, contradictory. Finally, where it leaves the future of adult social work does not appear to have been thought through with any clarity.

\section{Brokerage in the context of social work}

A standard dictionary definition informs us that the noun 'broker' refers to 'a person who buys and sells goods or assets for others'. The verb means to 'arrange or negotiate (a deal or plan)'. 'Brokerage' is the derivative noun (Oxford English Dictionary, 2005). This sounds quite straightforward. However, it would be naive to suppose that in social care work, brokerage is simply a neutral synonym for planning or negotiation. This would be to disregard the 'sedimentation' of cultural meanings that attach to words over time (Bakhtin, 1986). When 'brokerage' is entered in an internet search engine, the results are dominated by references to the world of commerce: investments, stockbrokers, mortgage brokers and so on-as one might expect. The weight of accumulated meaning strongly links brokerage to the business sphere and it is difficult to identify any obvious connections to social care, social work or, indeed, the public sector in general.

In the Thatcherite period at the beginning of the 1980s, with social work going through one of its many professional identity crises, Davies (1981) wondered whether social work should be regarded as 'brokerage in shades of grey?' He suggested that 'Social workers are brokers in lesser evils, but in being so they are only engaging in the compromises of real life, participating in the search for partial solutions to often intractable problems' (Davies, 1981, p. 31).

However, since this particular reference, social work texts that refer to 'brokerage' are noticeably scarcer than those that do not. The relatively small number that do (e.g. Payne, 1995) mainly appear in the period just after the official introduction of 'Community Care' in 1993, with the introduction of 'care management'. However, this specific period apart, neither 'broker' nor 'brokerage' is a term indexed in most standard social work texts of the 1970s, 80s, 90s or 2000s. These terms, for example, do not appear in the Collins Dictionary of Social Work (Pierson and Thomas, 2002). One might expect to see some mention in John Harris's The Social Work Business (Harris, 2003), but this is not so. Ironically, the latest Blackwell Companion to Social Work (Davies, 2008) has nothing indexed either. Historically, brokerage has largely been a concept absent from social work texts. However, there is evidence that this is now changing. Perhaps unsurprisingly, it can be found in a text published in 2008. According to Thompson and Thompson (2008), the brokerage role in social work emerges as a consequence of the changes brought about by the 1990 NHS and Community Act, in particular the 'purchaser/provider split'. They state:

One outcome of this change has been the creation of an added responsibility for many social workers, that of brokerage. The organizing of individualised packages of care in response to complex and unique needs requires someone to act as a broker...Social workers find themselves having to deal with competing obligations: on the one hand, acting as advocates on behalf of disadvantaged people who find themselves in vulnerable circumstances, but also, on the other hand, as gatekeepers of limited resources...brokerage in the form of care management has become a key feature of the social work role...(Thompson and Thompson, 2008, p. 166).

The authors' comment about the 'competing obligations' is important because, for some, the obligation to 'gate-keep' rules out the possibility of social workers completing the rest of the role, as will be discussed. However, whether 'brokerage in the form of care management' has become 'a key feature of the social work role' is a very moot point. It is doubtful whether many care managers would see their role in terms of brokerage, either now or when care management was first introduced (Carey, 2003; Dustin, 2007). Nevertheless, whoever performs the role, 'brokerage' has emerged in the context of an adult social care system in England that is now highly commodified and marketized. Therefore, the traditional commodity market interpretation might appear to be very applicable. 
What problematizes this analysis is the existence of a discourse of brokerage that has nonmarket connotations but that has largely been invisible in mainstream social work discourses. Brokerage has featured strongly in discourses of both independent living and disability rights for three decades (Brandon, 1995).

\section{An alternative discourse}

The development of models of brokerage can be traced to North America-with 'service brokerage' said to have been developed in Canada, where, as far back as in the late 1970s, individualized funding schemes have a longer history (Lord and Hutchinson, 2003; Reynolds, 2006). In fact, within the Independent Living movement in the UK, brokerage discourse predates the introduction of community care in the early 1990s (Salisbury, 1989). When community care was introduced, official guidance was more or less silent on brokerage (Department of Health, 1991a, 1991b; Department of Health/Social Services Inspectorate, 1991). However, during this period, models of brokerage were being actively discussed within the disability movement as the preferred way forward for independent living (Dowson, 1995). There was some early discussion-mainly outside of official circles-about care management performing some sort of broker role. However, it never became established and quickly disappeared from view. A few forward-thinking writers anticipated the debates that are only now beginning to take place. In 1995, somewhat presciently, Brandon took the view that:

\footnotetext{
Plainly, brokerage needs individualised funding more than individualised funding needs brokerage. And it is possible for organisations, care managers or disabled people themselves to re-frame the role of broker into an advocate. However, individualised funding for service users cannot be compromised although we still have to see whether it will be complemented by a worker with a role as a broker, advocate or care manager. The term service broker itself might not survive the next few years because of its association with business practice (Brandon, 1995, p. 6).
}

'Support Brokerage' has now re-emerged on the back of the personalization agenda that is, of course, essentially based on individual funding. Historically, then, when brokerage is talked about, it has generally been within disability rights discourses and outside of conventional social work discourses. Whether this is because of its associations with business practice or otherwise is difficult to say. The point is, with the exceptions already mentioned, the language of brokerage is relatively alien in the context of social work. That is, until recently.

\section{A modern social care discourse}

In 2006, care services minister, Ivan Lewis, outlining his vision for the future of social care, explained that:

Individual budgets, direct payments and In Control are not experiments-they are the ingredients central to a modern social care system. I intend to bring them together under a new people power banner to ensure cohesion, tackle any barriers to their progress and create a strong sense of mission. I also intend to explore the role of advocacy and brokerage in supporting people to take more control (Community Care, 2006, p. 32).

Individual Budgets, Direct Payments and In Control are the drivers of the personalization agenda. They are all examples of self-directed support, each having their own history and different philosophies. Direct Payments first arrived in the UK in 1996. Direct Payments were, when first introduced, primarily aimed at younger physically disabled people as a step towards realizing Independent Living. At this stage, 'personalization' had not entered the lexicon of social care. With the introduction of Direct Payments, support organizations were required to assist recipients with, amongst other things, accountancy, payroll and other services in order to help with the recruitment of personal assistants. The lack of proper support has repeatedly been identified as a factor either in low take-up or Direct Payments not working satisfactorily (Davey et al., 2007a, 2007b). However, in terms of the language used, since their inception, Direct Payments have been more associated with 'support' (Priestley, 1999) rather than 'brokerage'. 
In Control (2008) began in 2003 as a development of the Inclusion Movement for people with learning disabilities (Poll et al., 2006, p. 3). Individual Budgets, currently on the point of being 'rolled out' nationally, are a hybrid of the two. While Direct Payments have always been associated with the need for adequate support, support-brokerage appears to be more closely associated with these latter developments.

The emergence of a brokerage discourse in the context of mainstream British social care is therefore comparatively recent and can be traced to the Green Paper on adult social care, Independence, Well Being and Choice (Department of Health, 2005). This is where we first see the concept of brokerage, appropriated from its disability movement origins, and utilized in the context of modernization. In many respects, the Green Paper was stronger on 'vision' than on specific details. However, amongst other proposals, it talked about the introduction of 'a care navigator/broker model', where a 'care broker' is someone 'who might help the individual formulate the care plan, negotiate funding and help organise and monitor services' (Department of Health, 2005, p. 36).

It is unclear from this statement to what extent a 'care broker' role is intended to differ from a 'care manager' role. In official guidelines, the key activities of care management are assessment, planning, monitoring, implementation and review (Department of Health, 1991a). Whether 'help formulate the care plan' has anything to with assessment is not clear. It is also not entirely clear what 'negotiating funding' means. What the negotiations consist of and with whom are not immediately apparent. In any event, there would appear to be a degree of overlap between care management and care brokerage. It could be that, in essence, the roles are broadly the same, despite the different labels.

Langan (2000) explains how the agenda to modernize social services has mobilized a 'discourse of failure' to justify reform. Therefore, to a degree, the adoption of hitherto new words such as 'personalization' and 'brokerage' in social care can be seen as a discursive strategy that, somehow, suggests a new and better future. As far as 'brokerage' is concerned, the newness of the word is important because it represents a break from past failures, but so, too, are the vagueness and malleability of the term. It allows policy makers to suggest that great transformations (e.g. 'people power') are just around the corner, without spelling out exactly how they will take place. The lack of any past associations between brokerage and social work are important in this respect. It suggests that brokerage can do what social work could not-which may or may not prove to be the case.

The Commission for Social Care Inspection (CSCl) launched a discussion paper on 'Support Brokerage' in 2006. Emphasizing strong messages of involvement, control and choice, it explains that:

Brokerage is defined here as a function of social care which supports people with social care needs to navigate and choose the social care that best meets their assessed needs. It ensures they are fully involved and in control throughout choosing the care package and in its delivery (CSCl, 2006, p. IV).

However, some of the power and clarity of this vision begin to slip when one reads on to discover:

It is not yet clear where brokers will come from, who will recruit, train and pay them (and on what basis), whether they will be self-employed or employed by a service provider or by the council or whether the brokerage function will be operated by social care professionals $(\mathrm{CSCl}$, 2006, p. IV).

The $\mathrm{CSCl}$ document is, of course, only a discussion paper and not a policy document.

As noted previously, part of the appeal of brokerage is that it is flexible and has no single definition. However, it is this general fuzziness that has left commentators worried about how to turn good intentions into something concrete and workable. For example, Beresford (2007), among a raft of other questions, asks 'Where will control really lie-with the service user, or 
with carers and brokers? And where will all the brokers required come from, and how will their independence be assured?'

\section{Ambivalence over independence and professionalism}

At present, Beresford's concerns cannot be answered satisfactorily-on any question. As far as assuring broker independence, both the CSCl paper and, more recently, Transforming Social Care (Department of Health, 2008b) clearly articulate the belief that it is possible for brokerage 'to be operated by social care professionals'. However, the ambivalence about professional and/or 'de-professional' brokerage is again evident when $\mathrm{CSCl}$ declare that 'the de-professionalized role of the independent broker has considerable appeal' (CSCI, 2006, p. 29). This provides further evidence of the fundamental uncertainty about where brokerage belongs, organizationally, ideologically and professionally.

The CSCl statement raises a set of important (and, as yet, unsettled) questions, beginning with what 'professional' actually means as far as brokerage concerned. Does it mean professional in the sense of being paid, or does it mean professional in the sense that the broker is guided by a particular professional ideology, draws on a particular body of knowledge and is bound by a particular code of practice? If it is the former, then it would depend on what funding arrangements were in place as to how 'independent' the broker could be. If it is the latter sense, then it is important to identify what that particular ideology and knowledge are that guide practice. Interestingly, the underlying value and knowledge base of support brokerage are, in fact, very similar to those of social work. The overlap is acknowledged by CSCl, who state that 'In many respects, [support brokerage] is a relatively new term for some familiar models and concepts, rather than a wholly new idea; for example, the function encompasses some of the traditional skills and functions of social work' ( $\mathrm{CSCl}$, 2006, p. 3).

However, if support brokerage is a form of social work, there is a reluctance to talk about it in these terms. The impression the CSCl statement gives is that, whilst they believe that brokerage could be said to encompass 'some of the traditional skills and functions of social work', they do not believe it is actually social work.

Support brokerage has developed on a small scale, separate from social work, with its own traditions, its own codes of practice and ways of working (Dowson, 2008). However, within the official promotion of personalization, where it is often said that the government expects 50 per cent of adult social care users to be using Individual Budgets by 2009, support brokerage now takes a much more central position in adult social care. This not only raises the question of where and how support brokerage can work alongside social work but, more importantly, where it leaves the users of support brokerage in terms of protection against bad practice, their rights to complain and issues of accountability and quality assurance more generally. Dowson (2007) provides the perspective of the independent Support Brokerage Network:

Support Brokers are offering a professional service, in the sense that they should be operating within a context of regulation that ensures minimum competences, accountability to each customer; and safeguards.

The challenge for the development of Support Broker resources is to make sure that Brokers don't become 'professionals' in the negative sense of remote, bureaucratic, and unaccountable to the people they supposedly serve (Dowson, 2007, p. 2).

Dowson continues:

National policy needs to address the danger of Support Brokers becoming 'professionalised' in a negative sense, by giving responsibility for the support and regulation of local Brokers to disabled people, family members, and their community allies (Dowson, 2007, p. 2).

The latter statement is vague on detail as to how such regulation would actually work. Dowson (2008) has subsequently returned to explore the issue of the training and accreditation of independent support workers in more depth. However, the dilemmas of how and/or whether to professionalize independent brokerage are far from resolved in his report. 
The outcome was to recommend different possible options (some contingent on future developments) rather than come to any firm conclusions. Both his critique of professionalism (Dowson, 2007, 2008) and the earlier reference to the appeal of the 'de-professional' in the $\mathrm{CSCl}$ discussion paper have strong resonances of similar critiques of social work from the radical social work perspective - at least linguistically (Bailey and Brake, 1975; Mclntyre, 1982; Payne, 1997; Ferguson, 2008). However, the emphasis on the individual rather than the collective sets it apart in many important ways. If support brokerage does promise a form of emancipation, it is more based on consumerism and entrepreneurship (Harris, 2004; Ferguson, 2005; Scourfield, 2007) than fighting oppression through collective struggle.

It is not the intention here to discuss whether personalization through brokerage has more or less emancipatory potential than radical social work. Rather, it is to make the point that concerns about the professionalization of support brokerage echo similar debates and dilemmas that have arisen in social work over many years (Harris, 2008). The dilemma over professionalism illustrates a knotty issue at the heart of modernization. Modernization demands a workforce that is accountable, vocationally trained and registered (i.e. professionalized). Modernization is also about ensuring national standards. However, the rhetoric of modernization (and personalization) is loaded with references to giving service users choice, control and independence. Whether a professionalized workforce can truly bring about the empowerment of service users is therefore a highly contested issue. For example, on a closely related matter, opinion is divided over whether the personal assistants of people who receive DPs and IBs should have to be Criminal Records Bureau (CRB) and Protection of Vulnerable Adults (POVA) checked and/or registered (Community Care, 2008b). This debate raises important issues of where to locate accountability, responsibility, choice and control. Calling social work activities by another name-independent support-does clearly not solve the dilemmas associated with professionalization. Renaming merely displaces such dilemmas elsewhere.

In 2006, the Care Services Improvement Partnership (CSIP) produced a document drafted by Jenny Morris and Steve Strong 'to provide a starting point for the Individual Budget pilot areas to think about the role of service brokerage' (CSIP, 2006, p. 1). In this document, they admitted that 'Some people think there is a clear definition of service brokerage-and some people disagree about what this definition is' (CSIP, 2006, p. 3).

However, they go on to stress that, whatever model is adopted, key underpinning features of effective brokerage are:

- it is independent of the resource allocation process,

- it is independent of services (CSIP, 2006, p. 3).

Consequently, in this document, we see the ethos of the Independent Living movement coming through quite strongly in many ways-particularly on the independence of brokerage. However, in 2008, in Transforming Social Care, the Department of Health set out its vision for adult social care. In this document, we learn that 'The role of social workers will be focused on advocacy and brokerage, rather than assessment and gate keeping' (Department of Health, 2008b, p. 4).

These two extracts crystallize the ongoing confusion over not only what brokerage is exactly, but also where it should be situated professionally and organizationally. Incidentally, if social workers are no longer to be focused on 'gate-keeping', then the question arises-who is? With increasing demand, the need to ration scarce resources is greater than ever. Maybe this will spawn another type of quasi-professional social care worker.

\section{Models of support brokerage}

A consensus therefore currently exists that there is no single model of support brokerage. Six different models of support brokerage are identified as either being used, or as having been used in the UK, all of which involve different degrees of professional input (Research in Practice for Adults (RIPFA), 2008). There are: 
- Independent brokers who are either self-employed or who are working for a local or national voluntary agency which does not provide direct support services itself.

- Independent advocacy agencies which either employ brokers, or where advocates act as brokers for some of their time.

- Service providing agencies which provide Support Brokerage for people using their services, or for people using the services of other agencies.

- Local authorities where care managers carry out the Support Brokerage function, or where the function is separated out from the resource allocation responsibilities within the authority.

- Families who carry out the Support Brokerage responsibilities for their family members, or where families or disabled individuals form small local organisations to deliver Support Brokerage, and other functions, to a wider group of family members in a single community.

- A local authority or a prescribed area within a local authority where the full mix of all of the types of Support Brokerage is encouraged (RIPFA, 2008, p. 3).

This typology only serves to underline what a protean concept brokerage is. The range of people who can provide brokerage and the range of settings in which they work (either paid or unpaid) is about as wide as one could possibly imagine. RIPFA state quite openly that 'In the UK the position is that anyone can take part in delivering Support Brokerage' (RIPFA, 2008, p. 8).

Therefore, there is no formal brokerage job specification as such. A broker is not required to be qualified in anything in particular. This, of course, returns us to questions of how to ensure broker competence and how to establish some form of accountability in order that service users can confidently know what to expect. On this, RIPFA state:

Whilst there is a strong argument that people providing this specialist service should be skilled, trained and should meet a set of quality standards, the individual budget-holder would be the one to decide who should act as their broker (RIPFA, 2008, p. 8).

Considering the growing importance of the role, one would expect some guidance to be available that sets out how the role should be approached, in order to inform and protect both practitioner and service user alike. Whilst there is nothing from government, several examples of such guidance can be found in the brokerage literature.

Andy Gilbert, who is both a consultant and co-ordinator for the National Brokerage Network, provides a detailed outline of the desirable values, skills and qualities that an independent service broker might be expected to possess (cited in Reynolds, 2006). Similar versions can be found elsewhere (Dowson, 2008; National Brokerage Network, 2008). For the purpose of this discussion, the Gilbert outline can be taken as representative. From this, it is possible to identify what might be considered support brokerage's underlying occupational skill-set, value and knowledge base. According to Gilbert, the desirable personal qualities and skills of a broker are:

- A value system that recognises the inherent worth and uniqueness of the person and his/her right to full integration, autonomy and self-determination.

- A fundamental commitment to empowering people with disabilities (and their networks), while safeguarding basic human rights.

- Unequivocal acceptance of individual right [sic.] to make decisions impacting on his quality of life, meaning that planning support must be provided in ways that do not impose the broker's personal needs and professional judgement.

- An array of personal attributes and skills, including tact, diplomacy, initiative, sound judgement, a high energy level, tenacity, empathy, listening skills, flexibility, objectivity, ability to relate to others, warmth, sensitivity, patience, a sense of humour, perseverance, integrity and trust (Reynolds2006b, p. 11).

The list of values, qualities and skills that Gilbert considers appropriate for brokerage would not look out of place in the National Occupational Standards for Social Work (TOPSS, 2002). The point about the value system could come straight from a classic social work text such as 
Biestek (1957) or Butrym (1976). What possibly disrupts the idea of an 'exact fit' is the point about support being provided in ways that 'do not impose the broker's personal needs and professional judgement'. What 'professional judgement' means in the context of support brokerage is hard to determine, for reasons discussed earlier. However, social work does have a professional position. Whilst its values are mostly in accord with those outlined above, in social work, there is always the question of the 'dual mandate'. That is to say that whilst there is accountability to the individual, there is also accountability to the employing organization and the laws and policies that guide it. Herein lies a significant sticking point for many advocates of support brokerage in that, to work effectively, the broker must be accountable solely to the individual for whom they work (Brandon, 1995). However, if brokers remained independent but professionalized, presumably, they would also be accountable to their profession or at least to their employing organization. If independent brokers belong neither to a profession nor to a recognized brokerage organization, then one wonders how accountable their practice can be. The idea of broker independence has a seductive appeal in the era of 'people power'. However, this may not always necessarily work in the interests of service users.

Gilbert lists the following knowledge requirements for effective support brokerage:

- An understanding of the social and psychological processes through which people meet essential needs and develop their capabilities;

- A working knowledge and understanding of relevant legislation, social policies and services (and their associated criteria)

- Practical experience and insight into the politics of how organisations, bureaucracies and systems work.

- Awareness of available generic community services and supports and how they can be accessed, as well as the other kinds of services and organisations that are relevant to meeting the identified wants and needs of the person and his/her family / friends and circle of support.

- An understanding of the concept of the 'circle of support' and its relevance to an individual's quality of life.

- A solid understanding of the principles of person centred planning (PCP).

- Sound general knowledge of the various fields pertinent to the community living needs of people with disabilities.

- A strong understanding of the principles, structures, and functions of Individualised Funding (Reynolds, 2006).

Again, were one to review the content of any social work qualifying programme, all of these points would be expected to appear on the curriculum. The concept of the 'circle of support' may not be widely known amongst all adult social care professionals, as it is particularly linked to the sphere of learning disabilities. However, any professionally qualified care manager should possess this knowledge and would probably see it as their professional knowledge base. Lastly, the professional and technical skills that Gilbert discusses are:

- Highly developed interpersonal communication skills;

- Ability to work systematically in collecting and interpreting information about specific resources;

- Able to work in a group in ways that is [sic] facilitative.

- Ability to document the planning process and its outcomes in ways which are precise, yet also support vitality and imagination (cited in Reynolds, 2006).

It has already been pointed out that there is a high degree of congruence between the statements on brokerage and the key roles found in the National Occupational Standards for Social Workers. The skills that Gilbert lists as desirable for support brokers are exactly the same as those of social care professionals. 


\section{Where to locate brokerage? The need for clarity}

New Labour's unambiguous commitment to individualized budgets has brought with it both a foregrounding and an official endorsement of 'brokerage'. For the first time, this has placed brokerage firmly within mainstream social care discourse. However, in doing so, the government has conflated discourses of markets and consumerism with those of disability rights and Independent Living. The official appropriation of brokerage, by the New Labour government, as a major means by which the personalization of social care will be implemented has blurred where brokerage belongs, who controls it and caused confusion about what its purpose is-particularly as far as the future role of social work is concerned.

The following definition of social work, originally developed by the International Federation of Social Workers (2000), is cited in the Statement of Social Work Roles and Tasks for the 21st Century recently published by the General Social Care Council:

The social work profession promotes social change, problem solving in human relationships and the empowerment and liberation of people to enhance well-being. Utilising theories of human behaviour and social systems, social work intervenes at the points where people interact with their environments. Principles of human rights and social justice are fundamental to social work (General Social Care Council, 2008, p. 9).

Support brokerage does not explicitly purport to promote social change, but it does promote the empowerment and liberation of people to enhance well-being. It appears that many support brokerage organizations are performing roles and taking over tasks that once would have been considered the preserve of social work. Arguably, it is social work, although whether independent brokers would agree with this proposition is debatable. They do not selfidentify as social workers.

This position currently has governmental endorsement, as support organizations are not inspected and regulated by $\mathrm{CSCl}$ (or any regulatory body). The situation is under review, although it looks as if brokerage will remain outside the regulatory gaze of the social care authorities. The following are included on a proposed list of services that would not need to be registered with the new Care Quality Commission:

- Direct Payment or personal Individual Budget advisory or similar services, for example, support for self-assessment of social care needs and arrangement of services to meet those needs (such as brokerage).

- Advocacy services-services supporting people in getting their voices heard (Department of Health, 2008a, p. 75).

Not only are brokerage organizations exempt from regulation and inspection, neither are those who work in support brokerage organizations bound by the GSCC Code of Practice. With greater flexibility to be able to be more 'hands on', solve problems creatively and provide advice and different types of support, independent support brokers are beginning to occupy the ground where care managers, demoralized by the weight of managerial and bureaucratic controls (Lymbery, 1998; Postle, 2001, 2002; Carey, 2003), would probably like to be. Yet, despite suggestions to the contrary, statutory workers will struggle to enter this territory fully, because of the conflicts associated with their other key roles-notably, assessment and gatekeeping. It is often argued that being 'independent' makes it easier to challenge the decision making and poor practice of professional bodies. Whether this official tolerance of independence can last indefinitely is uncertain, especially if social care workers challenge the competence and quality of the independent support brokerage they encounter. In order to ensure some benefit for service users, it cannot be a challenge in one direction only.

Reflecting on the way forward for adult social care, Cornes (2006) posed this question:

Should we support the introduction of a range of new 'professional' and 'non-professional' roles (e.g. appointing Navigators and Brokers to work alongside Social Workers/Care Managers)? 
Should we develop the role of the Care Manager in the Single Assessment Process (e.g. developing navigation and brokerage as skills which form part of the Care Manager's role)?

Two years later, it appears that little progress has been made in coming to any firm decisions. Where developments are taking place, financial constraints are suspected of influencing decision making (Ivory, 2008). For example, in August 2008, Wirral Council announced the cutting of twenty-nine qualified social work posts as part of its implementation of the personalization agenda. At the same time, it announced plans to deploy more non-qualified staff in advisory, navigating and planning support roles (Community Care, 2008c). With scarce resources at stake, it is not difficult to imagine an ideological and territorial battle emerging between the independent and the statutory sectors. The battle would be over whose role it is to meet the needs of adults, promote their independence and well-being, and help them stand up for their rights. Independent support organizations might well have the better claim. With a view to clarifying their role, professionally qualified social workers might infer that, with the expansion of independent brokerage, their role would diminish but consolidate around what is often considered to be a core social work activity-assessment. Yet, the Department of Health (2008b) appear to have placed a question mark against this assumption. In any event, the idea of self-assessment (RIPFA, 2006) has already questioned the need for assessment to be the preserve of professionals. These developments suggest that, once again, the future of social work is undergoing change and redefinition on terms not of its own choosing (Harris, 2008).

It would appear that, as far as both personalization and brokerage are concerned, fluidity, uncertainty and opacity are the watchwords. It is not clear where the funding will come from to develop properly adequate brokerage for all those who will need it. Whether this will divert funding from other social care work is also unclear. It is also not clear whether any specific training or qualifications will be required in order for brokers to practise. However, it appears that any such training or qualifications could well emerge separately from social work training. In a climate of scarce resources, how the respective proponents of 'support brokerage' and 'social work' position themselves could prove highly significant in the long term. The relationship between support brokerage and social work could produce a sound working partnership; alternatively, the two occupations could find themselves in conflict with each other.

Considering the critical role brokerage is supposed to play in underpinning personalization and making individual budgets work, certain fundamental questions need to be addressed. These include:

- For the sake of service users and those who act as brokers, can brokerage remain so vaguely defined and so unregulated?

- If brokerage starts to become regulated, then against which occupational standards and/or which professional codes should broker practice be measured and accredited?

- If independent brokerage develops its own code of practice, training and qualification, namely its own professional identity, what, if any, is its relationship to social work, given that, in many important ways, it shares the same goals, competencies, knowledge and value bases?

- Should brokerage not come under the same regulatory regimes as social work?

\section{Conclusion}

It is two rather large 'ifs' but, if the personalization agenda takes off and if it generally becomes accepted that key support and brokerage functions should be the preserve of independent organizations, then one must seriously question the future of social work with adults. In the future, presumably, registered social care workers will retain adult protection functions and cases that are considered 'complex' (whatever this may mean exactly). It may well be that other roles will possibly involve some kind of assessment and referral activity. Most referrals will then go to independent organizations who, for all intents and purposes, will be performing social work tasks according to social work values, using social work skills, but who not only do not identify with social work. They will exist outside of social work regulation 
and not bound by social work occupational standards. Alternatively, as we have seen, referrals for brokerage services may go to unqualified workers in statutory organizations. It remains to be seen whether either development would be unequivocally in the interests of the millions of diverse social care service users in the UK. Much is riding on getting 'support brokerage' right.

1. For a clear exposition of what DPs and IBs are exactly and how they are supposed to work in the UK context, see Community Care (2008a).

2. The concept of de-professionalization has elsewhere been understood to mean the process of taking decision making and discretion out of the hands of social workers by the increased exercise of managerial controls (e.g. Harris, 1998; Clark, 2005). In this paper, the term is not used in the specific context of managerialism-although that is not to dismiss its broader relevance to this discussion. Here, de-professionalization describes a process whereby activities and tasks that were once considered the preserve of a professional group are transferred to non-professionals.

\section{References}

Bailey, R. and Brake, M. (eds) (1975) Radical Social Work, London, Edward Arnold.

Bakhtin, M. (1986) Speech Genres and Other Late Essays, Austin, TX, University of Texas Press.

Beresford, P. (2007) 'State of independence: Individual budgets, where social care service users control the cash allocated to them, are being lauded: But are they just another attempt to cut costs?', The Guardian, 23 May.

Beresford, P. (2008) 'Fair shares: Personal budgets must avoid one size fits all', The Guardian, 23 January.

Biestek, F. (1957) The Casework Relationship, Chicago, Loyola University Press.

Brandon, T. (1995) 'Would you be a service broker? A future job for all-rounders with a earning for independence', Care Plan, 3(March), 9-12.

Butrym, Z. (1976) The Nature of Social Work, London, Macmillan.

Carey, M. (2003) 'Anatomy of a care manager', Work, Employment and Society, 17(1), 12135.

Clark, C. (2005) 'The deprofessionalisation thesis, accountability and professional character', Social Work and Society, 3(2), 182-90.

Commission for Social Care Inspection (2006) Support Brokerage: A Discussion Paper, London, CSCl. Peter Scourfield Page 17 of 20

Community Care (2006) 'My agenda for change', 19-25 October, 32.

Community Care (2008a), available online at http://www.communitycare.co.uk/Articles/2008/06/06/102669/direct-paymentspersonal-budgets-and-individual-budgets.html (accessed 5 August 2008).

Community Care (2008b) 'Registration of personal assistants: The great divide', available online at http://www.communitycare.co.uk/blogs/social-workblog/2008/07/registration-of-personal-assis.html (accessed 6 August 2000).

Community Care (2008c) 'Wirral to axe 29 qualified workers', 14 August, 5.

Cornes, M. (2006) 'Who needs advocates, navigators and brokers? Developing the role of the care manager in the single assessment process', Michelle Cornes Social Care Workforce Research Unit, presentation given 2 February.

CSIP (2006) Brokerage and Individual Budget Pilots, Care Services Improvement Partnership: Social Care Programme.

Davey, V., Fernandez, J.-L., Knapp, M., Vick, N., Jolly, D., Swift, P., Tobin, R., Kendall, J., Ferrie, J., Pearson, C., Mercer, G. and Priestley, M. (2007a) Direct Payments: A National Survey of Direct Payments Policy and Practice, London, PSSRU/LSE, May 2007. 
Davey, V., Snell, T., Fernandez, J.-L., Knapp, M., Tobin, R., Jolly, D., Perkins, M., Kendall, J., Pearson, C., Vick, N., Swift, P., Mercer, G. and Priestley, M. (2007b) Schemes Providing Support to People Using Direct payments: A UK Survey, London, PSSRU/LSE, September 2007.

Davies, M. (1981) The Essential Social Worker. A Guide to Positive Practice, London, Heinemann.

Davies, M. (ed.) (2008) The Blackwell Companion to Social Work, 3rd edn, Oxford, Blackwell.

Department of Health (1991a) Care Management and Assessment: Practitioners' Guide, London, HMSO.

Department of Health (1991b) Care Management and Assessment: Managers' Guide, London, HMSO.

Department of Health (1998) Modernising Social Services: Promoting Independence Improving Protection Raising Standards, Cm. 4169, London, TSO.

Department of Health (2005) Independence Well-Being and Choice: Our Vision for the Future of Social Care for Adults in England, London, TSO.

Department of Health (2007) Putting People First: A Shared Vision and Commitment to the Transformation of Adult Social Care, London, TSO.

Department of Health (2008a) The Future Regulation of Health and Adult Social Care in England: A Consultation on the Framework for the Registration of Health and Adult Social Care Providers, London, TSO.

Department of Health (2008b) Transforming Social Care, LAC (DH) (2008) 1, 17 January 2008, London, TSO.

Department of Health/Social Services Inspectorate (1991) Care Management and Assessment: Summary of Practice Guidance, London, HMSO.

Dowson, S. (1995) Means to Control: A Review of the Service Brokerage Model in Community Care, London, Values Into Action.

Dowson, S. (2007) 'Ten statements about support brokers', 28 February 2007, available online at http://www.nationalbrokeragenetwork.org.uk/documents/downloads/10 statements a bout support brokers.pdf (accessed 22 May 2008).

Dowson, S. (2008) Custom and Control: The Training and Accreditation of Independent Support Brokers, Ipswich, National Development Team. Page 18 of 20 Going for Brokerage

Dustin, D. (2007) The McDonaldization of Social Work, Aldershot, Ashgate.

Ferguson, I. (2005) 'New radical social work or consumerist con-trick? Making sense of service user involvement in social work', available online at http://www.tissa.net/archive/2005/Ferguson.pdf.

Ferguson, I. (2007) 'Increasing user choice or privatising risk? The antinomies of personalisation', British Journal of Social Work, 37(3), 387-403.

Ferguson, I. (2008) Reclaiming Social Work: Challenging Neo-Liberalism and Promoting Social Justice, London, Sage.

General Social Care Council (2008) Social Work at its Best: A Statement of Social Work Roles and Tasks for the 21st Century, London, General Social Care Council.

Harris, J. (1998) 'Scientific management, bureau-professionalism, new managerialism: The labour process of state social work', British Journal of Social Work, 28(6), 839-62.

Harris, J. (2003) The Social Work Business, London, Routledge.

Harris, J. (2004) 'Consumerism: Social development or social delimitation?', International Social Work, 47(4), 533-42.

Harris, J. (2008) 'State social work: Constructing the present from moments in the past', British Journal of Social Work Advance Access published March 12, 2008.

Henwood, M. and Walker, N. (2007) Personalisation of Social Care and the Future of Care Management: Reflections from a Care Services Improvement Partnership Seminar, 19 July available online at http://icn.csip.org.uk/ library/Personalisation of Social Care.doc

In Control (2008), available online at http://www.in-control.org.uk

International Federation of Social Workers (2000), available online at

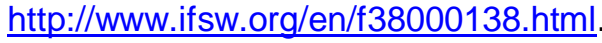

Ivory, M. (2008) 'Beware the bureaucrats', Community Care, 14 August, 4. 
Langan, M. (2000) 'Social services: Managing the third way', in Clarke, J., Gewirtz, S. and McLaughlin, E. (eds), New Managerialism, New Welfare? London, Sage.

Leadbetter, C. (2004) Personalisation through Participation: A New Script for Public Services, London, Demos.

Lord, J. and Hutchinson, P. (2003) 'Individualized support and funding: Building blocks for capacity and inclusion', Disability and Society, 18(1), 71-86.

Lymbery, M. (1998) 'Care management and professional autonomy: The impact of community care legislation on social work with older people', British Journal of Social Work, 28(6), 863-78.

McIntyre, D. (1982) 'On the possibility of "radical" case work: A "radical" dissent', Contemporary Social Work Education, 5(3), 191-208.

National Brokerage Network (2008) 'Person specification: Support broker', available online at http://www.nationalbrokeragenetwork.org.uk/documents/downloads/person specificat ion.pdf (accessed 25 August 2008).

Oxford English Dictionary (2005) Compact Oxford English Dictionary of Current English, 3rd edn, Oxford, Oxford University Press.

Payne, M. (1995) Social Work and Community Care, Basingstoke, Macmillan.

Payne, M. (1997) Modern Social Work Theory, 2nd edn, Basingstoke, Macmillan Palgrave.

Pearson, C. (ed.) (2006) Direct Payments and Personalisation of Care, Edinburgh, Dunedin Academic Press.

Pierson, J. and Thomas, M. (eds) (2002) Dictionary of Social Work, 2nd edn, London, Collins. Peter Scourfield Page 19 of 20

Poll, C., Duffy, S., Hatton, C., Sanderson, H. and Routledge, M. (2006) A Report on In Control's First Phase 2003-2005, London, In Control Publications.

Postle, K. (2001) 'The social work side is disappearing: I guess it started with us being called care managers', Practice, 13(1), 13-26.

Postle, K. (2002) 'Working "between the idea and the reality": Ambiguities and tensions in care managers' work', British Journal of Social Work, 32(3), 335-51.

Priestley, M. (1999) Disability Politics and Community Care, London, Jessica Kingsley.

Rabiee, P., Moran, N. and Glendinning, C. (2008) 'Individual budgets: Lessons from early users' experiences', British Journal of Social Work Advance Access published March $17,2008,1-18$.

Resolution Foundation (2008) LOST: Low Earners and the Elderly Care Market, London, Resolution Foundation.

Reynolds, I. (2006) Systems of Support and Brokerage: Independent Brokerage: An Exploration of Models, West Sussex, West Sussex County Council in partnership with ILA and ACE National.

RIPFA (2006) Self Assessment: How Does It Work, Is It Effective and How Can It Be Promoted? Outline 2, Totnes, Research in Practice for Adults.

RIPFA (2008) Support Brokerage, Key Issues 02, Totnes, Research in Practice for Adults.

Salisbury, B. (1989) 'Towards dignity and self determination', Community Living, October.

Scourfield, P. (2007) 'Social care and the modern citizen: Client, consumer, service user, manager and entrepreneur', British Journal of Social Work, 37(1), 107-22.

Thompson, N. and Thompson, S. (2008) The Social Work Companion, Basingstoke, Palgrave.

TOPSS (Training Organisation for the Personal Social Services) (2002) The National Occupational Standards for Social Work, Leeds, TOPSS. Page 20 of 20 Going for Brokerage 